\title{
Impacts, vulnerability and adaptation to climate change in Brazil: an integrated approach
}

\author{
José Antônio Marengo \\ Saulo Rodrigues-Filho \\ Diogo Victor Santos ${ }^{c}$ \\ ${ }^{a}$ Center for Monitoring and Early Warnings of Natural Disasters - Cemaden, \\ São José dos Campos, SP, Brazil \\ E-mail: jose.marengo@cemaden.gov.br \\ ${ }^{b}$ Sustainable Development Center, University of Brasilia (CDS/UnB), Brasília, DF, Brazil \\ E-mail: saulofilhocds@gmail.com \\ 'Ministry of Science, Technology and Innovations (MCTI), \\ Brasília, DF, Brazil \\ E-mail:diogo.santos@mctic.gov.br
}

doi:10.18472/SustDeb.v11n3.2020.35624

This dossier aims at presenting progresses in knowledge production on the identification of impacts and vulnerability assessment as essential steps for planning and implementing adaptation to climate change in Brazil. In this regard, it contains articles organized with elements from studies on Impacts, Vulnerability and Adaptation (IVA), which have been commissioned in the scope of the project that guided the preparation for the Fourth National Communication of Brazil (4NC) to the United Nations Framework Convention on Climate Change (UNFCCC). The $4 \mathrm{NC}$ is a government document, coordinated by the Ministry of Science, Technology and Innovations (MCTI in the Portuguese acronym), and is supported by the United Nations Development Program (UNDP), funded by a donation from the Global Environment Facility (GEF), and in partnership with the Brazilian Network on Global Climate Change Research (Rede CLIMA) ${ }^{1}$.

The present study adopted an interdisciplinary strategy based on the Nexus+ integrated approach aiming to assist the integration of public policies around the adaptation agenda in Brazil and reflect the progress in the science towards assessing and managing climate-related risks.

According to the contribution of the Working Group II to the Fifth Assessment Report of the Intergovernmental Panel on Climate Change (IPCC), in the face of deep uncertainty scenarios, it is recommended that conceptual models start from decision-making, or "policy-first", instead of those that start from the investigation of more direct causal relations, or "science-first". The latter are more oriented towards supporting the formulation of incremental adaptation actions, while the former require knowledge of this theme's complexity and represent a more systemic perspective. As per Figure 1, the further it moves to the right, towards greater integration, the more "policy-first" models become applicable.

1| The authors are responsible for the data and analyses presented herein, which do not necessarily express the position of the institutions involved. 


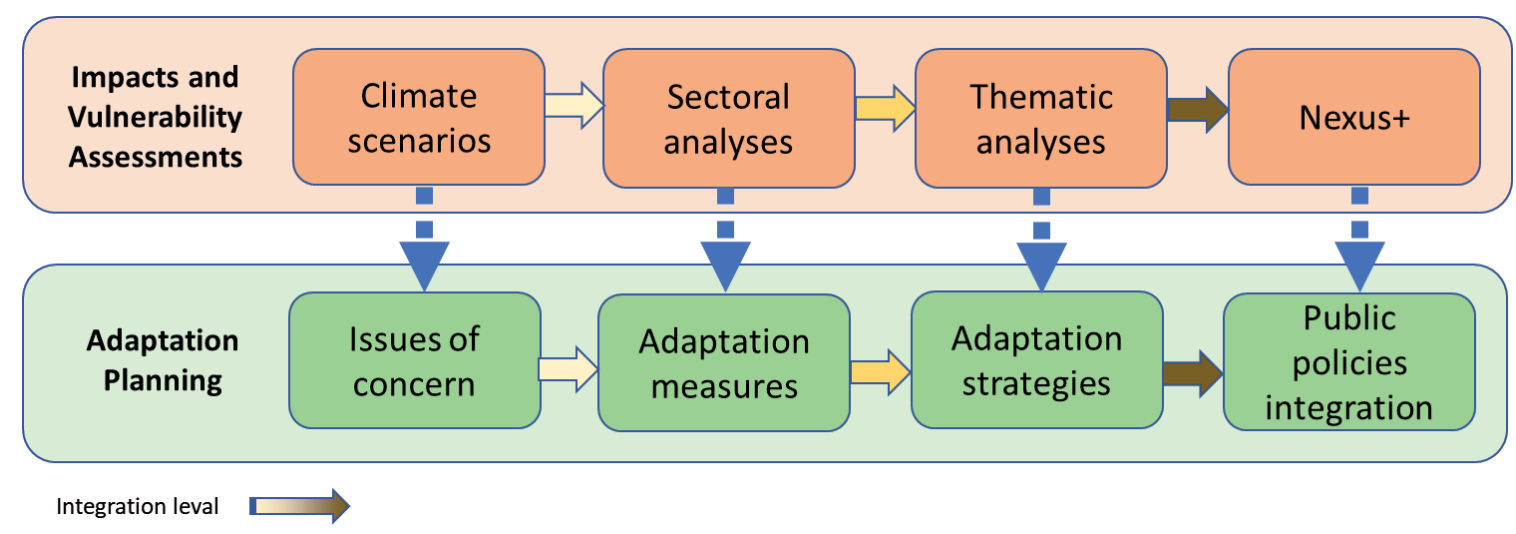

Figure 1 | Impacts and vulnerabilities assessments as background for adaptation planning (relationships in blue arrows), according to the integration level.

Source: Elaborated by the authors.

Using the Nexus+ approach led to structuring IVA studies around water, energy, food and socioenvironmental securities (ecosystem services, disasters and health), with territorial sections to be analysed per Brazilian biomes, coastal zones and cities.

Climate-related impacts that have already been observed within the Brazilian territory were considered, as well as global warming scenarios of $1.5^{\circ} \mathrm{C}, 2^{\circ} \mathrm{C}$ e $4^{\circ} \mathrm{C}$ above pre-industrial levels, or only SWL1, SWL2 and SWL4 (Specific Warming Levels²).

At first, the interrelationships among conditioning factors for risks or impacts were analysed in the scope of each security; then potential synergies and trade-offs were identified among the adaptation options related to the securities. The outcomes highlighted adaptation opportunities in line with environmental conservation, promotion of the country's socioeconomic development, and reduction of inequalities.

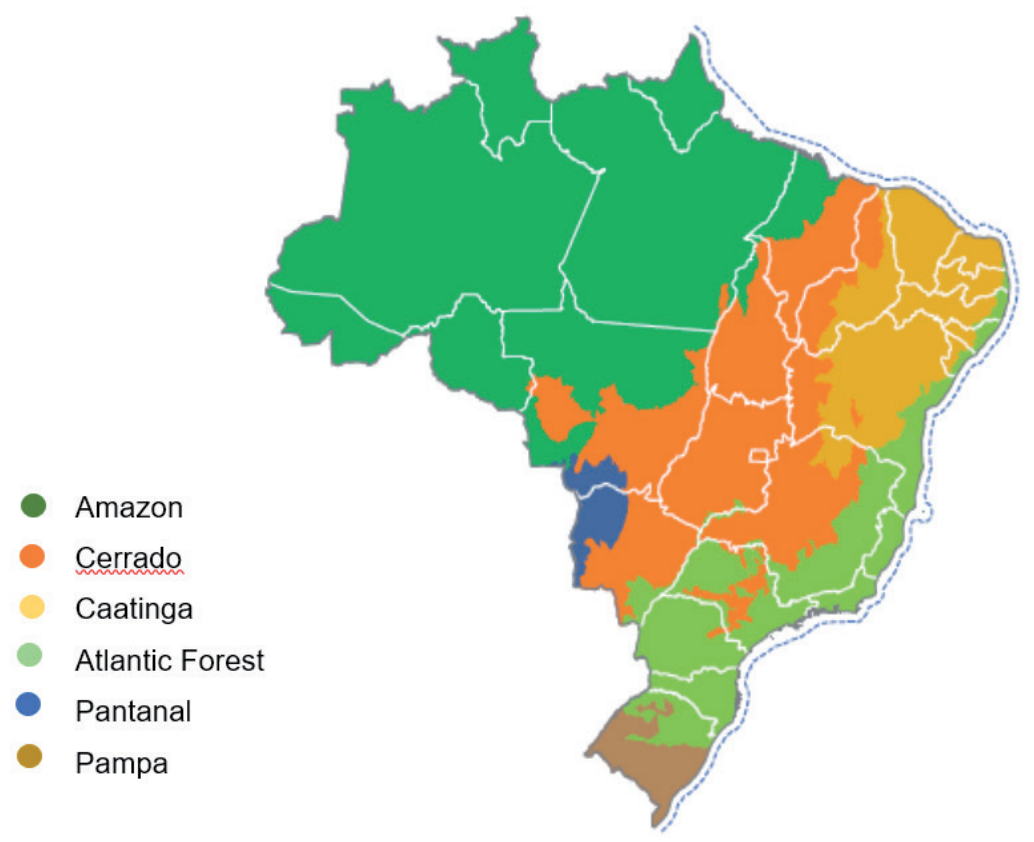

Figure 2 | Territorial division of Brazilian terrestrial biomes.

Source: Based on IBGE (www.ibge.gov.br).

2 | Variation of the global average anomaly of surface air temperature in relation to the pre-industrial period (approximately 1870-1899). 
Assessments and analyses focused on climate-related impacts and risks that require urgent action, taking into account the influence of climate and non-climate factors, according to the conceptual structure proposed by the WGII/AR5/IPCC (2014).

The series of articles begin with the description of the Nexus+ approach, followed by a description of the climate change scenarios used (according to Specific Warming Levels - SWL). As for the security analyses, the themes: water, energy, food and socio-environmental (disasters and health) securities are further explored. At last, aspects related to the coastal zones of Brazil are analysed.

The initial article (COUTINHO et al., 2020) details the methodological approach adopted in the development process of the studies on Impacts, Vulnerability and Adaptation, which supported the articles presented herein. It explains the conceptual choices and procedures that structured the work, as well as the innovation it represents.

Climate change projected among the different global warming levels has been analysed for rainfall, temperature and extreme climate indexes (dos SANTOS et al., 2020). The projections indicate robust differences in regional climate characteristics and include the following increments: in the minimum and maximum air temperature close to the surface to all the country's regions; in extremes of heat, particularly in northern Brazil, in the occurrence of intense rainfall in Southern and Southeastern Brazil; and in the probability of droughts and rain deficits in some regions of the Amazon and Northeastern Brazil.

Adaptation opportunities for water security in Brazil in the different biomes are covered in the correspondent article (PEREIRA et al., 2020). The expected reduction of water availability in future climate scenarios was discussed, considering not only changes in water supply but also the increasing projections of withdrawal within the next 20 years, and the current conflicts arising from multiple uses of water.

This suggests a scenario that amplifies the existing challenges for the near future. Water crises like the one that occurred in Southeastern Brazil during the summer of 2014 are likely to be more frequent in the future. Imbalances between the demand and availability of quality water in a multi-sectoral context underline the relevance of the integrated Nexus+ approach (which considers socio-environmental security together with the water-energy-food tripod, usually taken as pillars for the Nexus approach). Articulation among different institutions and public policies in multi-scale approaches (municipal, water basins, state and federal), as well as taking into account climate uncertainty when planning actions are challenges that still need to be overcome in managing water resources, which are crucial to guide adaptation actions.

Hydroelectric generation is responsible for supplying most of the electricity in Brazil, around $70 \%$. Like other renewable sources, water is highly sensitive to meteorological variables, so that climate change may have a considerable impact on it. The article assesses climate change impacts on hydroelectric generation and its consequences for the Brazilian electricity system (VASQUEZ-ARROYO et al., 2020). Scenario data for Specific Warming Levels (SWL2 and SWL4) are used, sourced from two regional climate models. Outcomes indicate that the electric system's adaptive capacity in light of the decrease in hydroelectric generation includes a growing penetration of other renewable and thermoelectric sources using natural gas, generating an increase in the system's marginal cost in order to meet the demand in 2030. In relation to greenhouse gas emissions, an increase in SWL2 scenarios is projected due to an increase in thermal power plant discharges, however with a reduction in SWL4 scenarios when other renewable sources (besides hydropower) have an increased share in the energy mix.

The occurrence and intensity of extreme climate events can also affect energy systems (VASQUEZARROYO et al., 2020). Impacts on hydroelectric generation, transmission and distribution systems, bioenergetic cultures and energy demand are assessed. The 2014 drought in Southeastern Brazil significantly reduced the average generation of the Três Marias Hydroelectric Power Plant (and other 
plants downstream) and also halted the 2014/2015 sugarcane harvest in the Center-Southern region. A heat wave in January 2019 might have caused a relevant increase in residential energy consumption in the Southeastern region.

Brazil is a major global food producer and stands out as a pillar for food security at a global level (CARVALHO et al., 2020). Occurrence of extreme climate events at present shows that climate is a challenge for the sector across the country, with consequences felt at the global context. Variations in the rainfall regime will directly affect food production, especially smallholders. Other extremes such as heat waves, landslides and floods may also affect food security, both in agricultural production as well as in transport and storage of products.

Different governmental agencies and programmes data, as well as climate projections made by the National Institute for Space Research (INPE, in the Portuguese acronym) were used. Especially in the past decade, results have shown the occurrence of great production losses with consequences in food prices due to droughts and other climate factors in several of the country's biomes. Important food crops in the Brazilian staple of food products, such as corn, beans, wheat and rice may be affected, mainly due to the water deficit associated with droughts, whose impacts vary depending on the region.

Climate change impacts on natural systems have been considered as one of the world's main environment transformation drivers (in addition to land use changes and other factors). This article addresses the concept of resilience that has been adopted in the scope of climate change and used in ecology to explain the ecosystem transition thresholds that, when crossed, would imply the inability of forests and other habitats to regenerate (while conserving their characteristic features) in the face of various external disturbances (PINHO et al., 2020).

The article uses a conceptual framework that combines the theory of critical transitions to distribution modeling in future scenarios, with the gradual increase of global temperature throughout this century, in order to show the way biome ecological resilience will be changed and what are the possible risks and repercussions for socio-environmental security in Brazil. The alternative of using biome resilience modeling is presented to point out possible paths for adaptive strategies, such as reforestation and the establishment of priority areas for conservation in the country.

The socio-environmental component also presents an analysis of Brazilian urban vulnerability to disasters (such as landslides and floods), based on impacts that have already been observed and mapped, in relation to present climate and future climate scenarios (PEREZ et al., 2020). The analyses considered the Brazilian social inequality context. Focus on socially vulnerable populations living at risk and the precarious urbanization process are fundamental aspects in order to understand climaterelated impacts in future scenarios.

Aspects of risk and exposure to heat stress conditions, and its potential repercussion in mortality from cardiovascular and respiratory diseases in Brazilian capitals are evaluated (OLIVEIRA et al., 2020). Depending on the warming level (SWL1,5, SWL2 and SWL4), a significant increase in heat stress is observed country-wide in the RCP $8.5^{3}$ scenario using the Wet Bulb Globe Temperature (WBGT) indicator, especially in the Northern and Center-West regions. Mortality from cardiovascular and respiratory diseases may increase depending on warming levels, and present different results among capital cities.

The Article of JACOBSON et al. (2020) assesses future global warming impact on the Years of Life Lost (YLL) due to heart diseases in adults ( $\geq 45$ years) and respiratory diseases in the elderly ( $\geq 60$ years) in every capital of Brazil. Rio de Janeiro and São Paulo presented the highest YLL index (attributable to global warming) for the scenarios evaluated (SWL1,5, SWL2 and SWL4). Results of this research suggest that the impact of exposure to temperature on YLL tends to increase as the level of global warming increases

3 | Representative Concentration Pathways (RCPs), correspond to peak stabilization scenarios, or late 21st century of the radiative forcing in $\mathrm{m} \mathrm{W} . \mathrm{m}-2$. In the case of RCP 8.5 , reference is made to $8,5 \mathrm{~W} . \mathrm{m}-2$. 
The article of CARVALHO et al. (2020) shows that climate change affects human health either directly or indirectly, and related impacts are complex and depend on several variables. The various climate change impacts on health include a change in the spatial distribution of vector-borne diseases, such as visceral leishmaniasis, yellow fever and malaria in Brazil, in different scenarios of global warming. In these future scenarios, visceral leishmaniasis found more favorable climate conditions in the Southeastern and Southern regions of Brazil, while climate in the Northern and Center-West regions gradually became more favorable to yellow fever. In malaria scenarios, an increase in favorable climate conditions to its high incidence in the Atlantic Forest biome was observed, where currently "extraAmazonian" cases occur.

The coastal zone, where most of the Brazilian population is concentrated, has a central role for the discussion of vulnerability and adaptation tools in the face of climate change (HORTA et al., 2020). Water ecosystems represent a source of food for humans and also the abundant and rich biodiversity in coastal environments. They also have the function to absorb and retain carbon dioxide, a greenhouse gas that plays a central role in climate change. Adaptation based on ecosystems must receive special attention in discussions that envisage the reduction of vulnerability and adaptation of coastal communities.

All the articles that make up this dossier propose adaptation measures to climate change and point at possible repercussions for water, energy, food and socio-environmental securities, and climate itself. In general, it may be stated that negative impacts and risks related to climate extremes and climate change surpass the benefits and are aggravated by anthropic pressure factors in all securities. This is manifested heterogeneously within the territory and according to socioeconomic conditions and biophysical characteristics. Adaptation implementation will be more efficient when it takes into consideration synergies and trade-offs, with the former prevailing over the latter, having been identified as more urgent the improvement in management capacities, reduction of structural vulnerabilities and maintenance of ecosystem services.

The work presented in this dossier brings innovative outcomes, mainly with regard to the integration among sectors and subjects, both in understanding impacts and risks as well as in proposing solutions. The process attempted to identify priority issues, where adaptation would be more relevant (in the different levels of warming assessed herein), in addition to exploring aspects to be considered in the scope of public management, in order to make these actions more effective, as well as to support different segments of the civil society and academy in comprehending problems and implementing adaptation options.

\section{Dossier Editors}

